\title{
Toward a Theory of Atypical Media Work and Social Hope
}

\author{
Mark Deuze*, Gemma Newlandsł, Johana Kotišováł and \\ Erwin van't Hofs,
}

\section{Abstract}

Most media work today takes place under atypical conditions, i.e. media professionals such as journalists, musicians, filmmakers, advertising creatives and game developers generally work without open-ended contracts. In this essay, a theory of atypical media work is outlined highlighting this way of working and being at work from the current culture of capitalism. Further, it also throws light on how dualisms, dominating the discourse on media work - such as contracted versus freelance labour, primary and secondary sector employment, good versus bad jobs, paid versus unpaid work - are not as useful as they seem to be is shown. It also delves into the different ways of making precarity, precariousness, constrained autonomy and lack of agency and highlights themas the key problematic features of atypical work - productive (beyond productivity narratives). Throughout the argument, the reasons and motivations for (doing and studying) atypical media work are articulated with a distinct sense of shared social hope.

Keywords: Media labour, atypical work, freelance, precarity, autonomy, journalism

\footnotetext{
* The University of Amsterdam, The Netherlands; M.J.P.Deuze@uva.nl

† BI Norwegian Business School, Norway

‡ Masaryk University, Czech Republic

$\S$ The University of Amsterdam, The Netherlands
} 


\section{Why Should We (Not) Study Atypical Work?}

This kind of work should not be studied because the often quite privileged middle-class students in our classrooms may not get their preferred 'dream job' more or less directly after they have left the classroom. Trade schools, colleges and universities already function as effective (and often exclusive) gateways to media work, becoming less accessible to a truly diverse range of people vying for creative careers. The majority of the kids in the courses and programmes of institutions of higher education (particularly in the Global North) will be fine. Working in the creative sector, the media in general and journalism, in particular, can be increasingly considered to be a luxury, only a few can afford. Subsequently, we should not be publishing about atypical work as a way of 'virtue signalling' to the industry and its critics, as this can lead to what Vicki Mayer describes as "bizarre forms of complicity" (2008: 145), with the scholar becoming enmeshed in the very control chain and subsequent uneven power relationships she is critiquing. As Gregg (2009) additionally articulates, we cannot be critical about industry production cultures without acknowledging our participation in a range of instances of atypical work and affective labour- accepting destructive work styles and accepting dire working conditions in the name of our intrinsic motivation.

Atypical work should be studied because its problematic features amplify and accelerate existing social inequalities (such as those that the media industry particularly suffers from like ageism, sexism, racism, and middle-classification). Most importantly, creative labour in general, and atypical media work in particular at this moment because it offers an opportunity to recognise the ambivalence of professional identity formation, to rethink precarity and make it productive, to recast agency into a complex anticipatory practice, and to develop a sense of shared and collaborative autonomy. All of these perspectives are not just useful for a theoretically rich understanding of (atypical) creative and media work but for our precarious lives today. These concerns frame the argument in this essay. 


\section{Social Hope and Engaged Scholarship}

A second framing device for the argument is a consideration of scholarship as infused with social hope. The deliberate linkage of theory and research with social hope is inspired by the work of Richard Rorty (1999), who calls on us in our work to hope for a change for the better in the present and a prospective of chances given to the future. Simply observing examples of exploitation or commenting on the superficial, crass and contingent nature of media management and work is not good enough. The wonder, awe and surprise as guides to explorative research and open-eyed observations are also appreciated (Witschge and Deuze, 2020). Hope inspires looking for solutions and the development of a moral consciousness that enables (with the workers we study and observe) to fight whatever evil can be found.

There are many examples of implicit hopeful perspectives in the literature on creative work. Ross (2008) for example, notes how the rise of atypical work in the creative sector reflects an uptake and infiltration of models of employment from the informal and secondary sectors of the economy, which includes a variety of professions and careers - including but not limited to low-wage (or no-wage) work (in domestic service, kinwork and caregiving), any kind of work not covered by formal law protections, typified by instability, underemployment and lack of potential to 'move up' and progress to more stable employment. There is potential for a common cause and 'fellow-feeling' here, Ross suggests, that could lead to cross-class coalitions and multiple forms of collective organisation (43).

Calling for research infused with social hope is a normative and ethical stance, one that emphasises engagement, a "staying with the trouble" (Haraway 2016), as well as a 'becoming-with' our objects of study (Ingold 2018), along with a deliberate focus on collective and shared notions of agency. This necessitates a look at labour and works beyond labour or subjectivist theories of value, embracing the lived experiences and "emotional responses" (Hesmondhalgh and Baker, 2010: 7) of the practitioners we study in all their complexity and inconsistency. A second implication is to integrate observing and interviewing our objects of study by engaging in 
their worlds. Jenkins, for example, passionately advocates media production scholars to participate in conversations with and in the industry, enabling academics to potentially influence the choices that emerge from those conversations: "It's pretty damn hard to speak truth to power when you refuse to even talk with anyone who has the power to act upon your concerns" (quoted in Deuze and Prenger, 2019: 478).

There exists a rich tradition of engaged and 'insurgent' scholarship, mainly inspired by knowledge production in feminist, indigenous and critical race studies. Such work advocates critical reflexivity, deploying participatory, experiential and action research methods, whereby challenging the status quo can become part of the scholarly pursuit. In studies of media work, Mark Banks (2017) for example calls on us to pursue and push for 'creative justice', meaning:

- respecting all the 'internal' benefits, capacities and pleasures such work provides, without discounting the 'external' structures and pressures (such as exploitation, alienation, low pay, stress) that can make media work deeply unfair and unjust (3);

- advancing social arrangements that allow for the maximum range of people to enter and participate in cultural work, in which they will be fairly treated and justly paid and rewarded for their efforts (5); and

- reducing the physical and psychological harms and injuries inflicted by cultural work, making sure that practitioners are treated fairly and justly as dignified and deserving human beings(5-6).

In our team, we take responsibility for this particular aspect of our projects in various ways like researching and working alongside our study participants, by using a variety of methods, including socalled 'creative methods' as a means of engagement to "support deeper understanding" by "involving academic and external audiences both analytically and emotionally" (Archetti, 2020)i, by translating' findings and insights into practical workshops and public talks; through participating actively in conversations with(in) the industry; by taking on both formal and informal roles 
in trade associations, boards, and councils; and through publishing and publicising our work beyond scholarly publications (such as via podcasts, blogs and vlogs, and through various social media, as well as in media appearances). In short, our call for social hope in production studies is a perspective grounded in engaged scholarship, based on the principles of creative justice, and anchored in respect for the experiences and stories of (individual) media workers - especially when it comes to concerns about (the rise of) atypical work.

\section{Atypical work}

The rise of atypical work or 'non-standard employment' (NSE) in the global economy is often considered to be a particular feature of what Sennett (2006) has called the 'culture of the new capitalism.' The gradual shift of more or less predictable career progression within corporate structures to unstable 'boundaryless' or 'spiral staircase' careers (where workers move around constantly without necessarily moving forward or gaining seniority) is attributed to a distinctly modern version of capitalism. The modern networked form of enterprise assumes that people should constantly adapt and prove themselves to be assets to an industry that loves to label itself as dynamic. Sennett particularly notes how elements such as craftmanship and mutual trust suffer in the process.

In a 2016 review of the state of atypical work around the world, the International Labour Organization (ILO) notes that although NSE is on the rise globally across all sectors - and especially in creative and service industries - exact figures are hard to come by. The ILO distinguishes four types of NSE, each with its own key problematic features:

1. temporary employment: fixed-term contracts, including project- or task-based contracts; casual work, including daily work; not open-ended.

2. part-time and on-call work: normal working hours fewer than full-time equivalents; marginal part-time employment, oncall work including zero-hours contracts; not full time. 
3. multi-party employment relationships: including 'dispatch', 'brokerage' and 'labour-hire', temporary agency work, subcontracted labour; based on a subordinate relationship with the end-user.

4. disguised employment/dependent self-employment: work that is not part of a formal employment relationship (including false employment, where a freelancer works for one company exclusively).

The umbrella-labelling of any kind of work arrangement other than an open-ended contract (OEC) as atypical or non-standard suggests that such features of employment in the labour market are somehow specific to contemporary working conditions across a variety of economic sectors. However, scholars, trade associations and activists in the field of labour have been documenting a wholesale shift toward more precarious, contingent and insecure working arrangements at least since the early 1970s, adopting as well as critiquing categories and concepts such as the 'informal economy', and the rise of a 'secondary sector' in the labour market consisting of workers with low-status jobs who make a low-tominimum wage, operate in poor working conditions, with poor job security and little opportunity for promotion. Similarly, the unusual dynamics of the so-called 'external labour markets' where workers constantly move from job to job and project to project between firms, rather than building a career within a company - have been extensively studied since at least the 1970s.

Although atypical work occurs throughout the labour market - and is generally more stringently articulated with the agricultural and service sectors of the global economy - the media industry has been historically organised along the principle of a boundaryless, spiral staircase and otherwise non-standard career trajectories. In a 2016 report on The Future of Work in the Media, Arts \& Entertainment Sectorin Europe, the authors signal both a long history of projectbased work and freelancing traditions in the sector, as well as an accelerating trend towards multiple forms of atypical work (Charhon and Murphy, 2016). Project-based and otherwise temporary or casualised work arrangements have long typified careers in film and television studios, as well as in agency work in the fields of advertising, public relations and marketing 
communications. This is a poignant feature of work for women and minorities in the media workforce.

Within the media, journalism occupies a particular place. Not only is the element of trust in news in decline around the world but also the work quality of journalists has also been consistently on the decline since at least the 1980s. In 2006, the International Federation of Journalists (IFJ) published a benchmark report on the global rise of NSE in journalism around the world. At the time, atypical media work was defined as the various types of employment that are not permanent and/or full-time, with a direct relationship between employer and employeeii. Examples of such atypical work relationships included short-term rolling contracts, subcontracted work, casual and otherwise temporary work, as well as freelance work and any kind of self-employment. About a third of the membership of IFJ affiliates in 38 countries was made up of these 'atypical' workers - a figure that has been growing since. In another cross-national assessment of the developments in journalism, Rottwilm notes a global trend where "forms of journalistic employment shift from salaried labour for large corporations to a more diverse range of forms of employment, including full-time positions, freelance labour, and selfemployment for a broad variety of organisations, including new forms of small start-ups, small- and mid-sized enterprises, and larger corporations" (2014: 11). It is noteworthy that such a concern about the rise of NSE in the news industry emerges at a time when such employment patterns become paramount for professionals working for newspapers, whereas the majority of professionals in the magazine, audiovisual and - since the late 1990s - online sectors have always known precarious working conditions in journalism.

The debate about NSE and creative work and media work (and more specifically, work and careers in journalism) in particular has predominantly been framed in normative terms, articulating crucial concerns about exploitation of workers, the lack of opportunities and incentives for collective organisation and bargaining, and the mental and physical health consequences of living in a state of perpetual insecurity. Scholarship has found significant levels of work stress associated with typical features of freelance media work, such as irregular earnings, over commitment, and low 
rewards (in terms of money, esteem, promotion prospects, and job security). Other studies on NSE and media work in recent years are similarly mapping less-than-ideal circumstances, contexts and consequences of such working arrangements for media professionals, highlighting the pressures and stress of 'making it work' and having to develop and sustain various coping practices. Trade associations have similarly begun to address issues regarding the mental health of media workers. A good example is the Whole Picture Programme(WPP) in the UK by industry association Film+TV Charity, developing a support program based on a survey of British professionals in film and television that showed $87 \%$ of this workforce having experienced mental health problems (compared with 65\% UK-wide; Wilkes, Carey and Florisson, 2020: 5). Interestingly, the program report signals "challenging and often damaging" working conditions as but one of three key causes of the "mental health crisis" in the audiovisual industry, the others being work cultures that tend to stigmatise health concerns, and a lack of support and capability to think and act differently. The academic attention for health issues in media work similarly notes how less-than-ideal working conditions are often not the primary concern for the practitioners involved - for whom intrinsic motivation, autonomy and meaningfulness tend to take primacy.

Despite these histories and traditions, there is still a theoretical deficit in explaining and, perhaps more importantly, changing the problematic circumstances of NSE. This deficit is the focus of this essay and consists of three key elements. First, the lack of reflectivity about the normative bias in discussions of NSE - of what constitutes quality work. Second, a similar lack of complexity in the various discursive categorisations used to typify creative work in general, and media work (including journalism) in particular. Third, the theorisation of NSE in media work tends to lack hopeful perspectives on collective action and transformation which would uncouple atypical ways of working from the culture of capitalism. Although we would not argue that nobody addresses these issues, it is just that such nuanced perspectives are often snowed under an avalanche of critical analyses that render the complex agency of media workers (as well as media consumers) almost obsolete. As Henry Jenkins states, such scholarly work in 
the field of production studies "underestimates the kind of critique that occurs amongst creative workers," instead of imagining "a world where those who make media are fully indoctrinated into the logic of the system" (quoted in Deuze and Prenger, 2019: 478).

Considering these developments and their significance for the study of media work generally, and NSE across the media industries, in particular, four key observations on creative labour generally - and media work in particular - regarding dualisms, ambivalence, precarity and agency as key problematic aspects of atypical media work that highlight the need for new research and theoretical development have been made below.

\section{Dualisms}

First, a remark about the less-than-useful binary opposition often maintained between 'typical' and 'atypical' working arrangements in the media - and between other dualisms when it comes to media work, such as between the wage employed and self-employed. To some extent, these can be considered to be 'zombie' categories (Beck, 2002): ideas that live on even though the reality to which it corresponds to, is dead. Although, in legal and economic terms, there is a distinct difference between being employed with an open-ended contract (OEC) and making a living as a freelancer, in practice both professionals experience various levels of unpredictability and pressure in the media. Whereas the selfemployed worker lives from assignment to assignment and generally is unable to plan much, the employee is not 'safe' either.

The last few decades in media work can be characterised by nearconstant re-organisations, managerial overhauls and otherwise disruptive interventions in the workplace, more often than not leading to forced lay-offs and early retirements, budget and salary cuts, job rotations and reassignments. Furthermore, for some of the employees with an OEC, their work-life isn't blissful in the least. The pressure to do 'more-with-less' is on, colleagues are being let go left and right, and the threat of automation and algorithmic control over creative decisions and the entire product cycle is quite real. Material security is another version of precarity as unpredictability affects all. So-called 'standard' employment can 
also be impacted by recessions, furloughs, redundancies and so on. This is particularly an issue with a rapid job change and automation where job roles are being replaced and shifted quite frequently. Ultimately, the less dependable jobs are often those governed by standard employment contracts. This points toward another dualism, between workers with contracts and those without, which ignores the rapid increase in fixed-term contracts (FTCs), sometimes for just a few weeks or months, as well as zerohour contracts with no minimum limits.

Paid versus unpaid work is another dualism to be deconstructed. Research identifies the unpaid dimensions of paid work that are crucial to being employed in the creative industries, such as emotional labour (Kotišová, 2020), excessive networking and relationship management (Fröhlich, 2007), and the mixing of family and household duties with work as professionals increasingly work from 'intimate' spaces such as the home (Gregg, 2011). This demands an intersectional approach to media work, considering how the crisscrossing of paid and unpaid work resonates with unequal distribution of caregiver burdens, home management, and so on.

In a groundbreaking study, Hesmondhalgh and Baker (2011: 39) developed a nuanced model of 'good' and 'bad' work in the media industry, suggesting that such operationalisation enables an effective critique of potentially unjust practices. Good work, they argue, contains elements such as good wages, working hours, high levels of safety and autonomy, experiences of interest and involvement, sociality, self-esteem, self-realisation, a decent worklife balance, some semblance of job security, and being part of a project or company that strives for excellence. On the other hand, bad work can be typified by instances of poor wages, working hours and levels of safety, feelings of powerlessness, boredom and social isolation, low self-esteem and shame, frustrating development and so on. An explicit conceptualisation of good and bad work seems particularly necessary when it comes to freelance and part-time media workers, as more often than not for these professionals "working in NSE is an explicit choice and has positive outcomes" (ILO, 2016: xxi), despite experiencing a "higher incidence of decent work deficits" (Charhon and Murphy, 2016: 5). 
However, as Hesmondhalgh and Baker also note, these categories are not mutually exclusive, not necessarily uniform in their meaning in everyday working contexts - a point to which we will return when we articulate the structural part ambivalence plays in making sense of atypical work.

A key challenge for media workers is how to collectively organise, stand together, and resist. Dividing the workforce along sometimes arbitrary or otherwise less than thoughtful lines does not help, and seems to reinforce divisions that the industry likes to make - for example by using a variety of payment, contractual and remunerative arrangements for professionals although they are essentially performing the same tasks (a practice quite common in both the audiovisual sector and throughout the gig economy).

\section{Ambivalence}

A second observation, by way of extending the argument against simplistic dualisms in classifying, categorising, and codifying media work, must be to move beyond black-and-white normative operationalizations of (atypical) media work. In several empirical studies among various groups of media professionals - in particular those in NSE contexts - it is the highly ambiguous, ambivalent, and contradictory nature of (the lived experience of) what working in the media is like that comes to the fore as an object requiring careful theorisation beyond $\mathrm{good} / \mathrm{bad}$ conceptualisations. As Kotišová (2019) points out, "the trouble with the good aspects of the labour such as autonomy and selfrealisation is their deep ambivalence and their susceptibility to the context rather than their inherently seductive and manipulative nature" (30).

Focusing our attention deliberately and specifically on the inherent ambivalence and context-sensitivity of (experiences and meanings of) media work is crucial. Simultaneously, we should not lose ourselves in the endless particularities of case studies. Paraphrasing C. Wright Mills (1959), we should strive to connect the personal troubles and experiences of the people whose precarious lives we observe to the social structure within which this takes place. Essentially, we need both the detailed stories of individual actors as 
well as a comprehensive appreciation of how they exist and function in a network of interdependence. To some extent, this points toward the age-old structure versus agency dilemma in social research, which Giddens (1984) resolved by calling researchers to be mindful of a continuous process of 'structuration' in which social structures and actors mutually constitute each other. In media studies, such a nuanced appreciation can be applied in production scholarship by applying practice theory, which bases research on the assumption that everyday actions are consequential in producing social life. As Raetzsch and Lünenborg (2020) argue, if we consider interactions, activities and conversations as constitutive of any kind of social order, the distinction between the 'micro' level of subjective experience and the 'macro' level of institutional structures disappears - as everything can be reduced to (more or less) routinised practices. What is additionally useful about using practice theory in production studies as a way to resolve the structure-agency dilemma, is that it shifts attention away from the exclusive confines of routines and rituals within institutional frameworks - such as the newsroom, the agency office, or the television studio - to include interactions, conversations and practices elsewhere, involving a much wider variety of actors (including the public) and settings within which media work takes place.

\section{Precarity}

The most consistent theme running through the literature in studies of (atypical) media work is precariousness and precarity. As with atypical work, it is a historical condition, explored in great detail since at least the 1960s by philosophers and economists alike (as well as by scholars in other fields). Generally speaking, precarity can be understood in two ways: first, as a specific consequence of the transformation of labour and the gradual retreat of the welfare state in the latter half of the $20^{\text {th }}$ century, exemplified by industrywide deregulation and the redistribution of risk and care away from employers and the state to the individual. This, in turn, contributed to a rise of atypical work arrangements. The second understanding of precarity refers to an ontological condition of insecurity and interdependency that does not just affect the world 
of work but pervades all other aspects of life. As Gill and Pratt attest, "This double meaning is central to understanding the ideas and politics associated with precarity; the new moment of capitalism that engenders precariousness is seen as not only oppressive but also as offering the potential for new subjectivities, new socialities and new kinds of politics" (2008: 3; italics in original).

At the heart of precarity is not so much having or not having a (contracted) job, but rather the experience of being unable to plan, control and predict what will happen next. When experienced as a structural condition of everyday life, precarity can contribute to a sense of 'ontological insecurity' eroding one's belief in the continuity, reliability, and consistency of oneself, other people, and things. Living through indeterminacy seems to be less the exception than the condition of our times. This brings into view people's feelings of vulnerability, displacement, and hopelessness.

The literature on precarity and precariousness focuses mainly on its debilitating features, limiting the capacity of workers to plan and control their work, pushing professionals to internalise the unsettling demands of structural discontinuity and 'permanent impermanence' (Deuze, 2012: 39). Additionally, as Banks argues, is that "the control and mastery of the temporal domain is something readily available, but only to the privileged few," which turns 'being able to work' in the media into something of a 'social luxury' (2019: 13). This argument is supported by numerous studies showing how access to work and jobs throughout the creative sector in general, and the media (including journalism) in particular, is increasingly determined by certain socio-economic indicators such as tertiary levels of education, gender and ethnicity, housing, and so on. Being able to afford to live in the world's metropolitan centres (as this is where most media companies are located), having access to (degrees from) reputable trade schools and colleges, and being part of a country's dominant social groups - which in the Global North generally means: being white and male - to some extent function as informal prerequisites for 'making it work' in the media industry. This additionally asks us to take an intersectional approach to theorise the media industry's 
relationship with precarity, as its root causes and consequences cut across a variety of social categorisations.

General theories of precarity omit the particular experiences of precarious life such as documented through ethnography. There is no 'one-size-fits-all' notion of precarity, which is especially important as it attunes us to examples of complex agency among those living in and through precariousness. Here we would like to suggest that this particularity points to what one could call the productive potential of precarity and precariousness. This potential has been signalled in the past - most notably in the work of Judith Butler (2004; 2016), where she identifies our common human vulnerability and interdependency as a potential source for a 'good life' based on radical democracy and collective organisation (for example through new social movements). Anne Allison also points to a more hopeful notion of precarity, observing "an emergent potential in attempts to humanly and collectively survive precarity: a new form of the commonwealth (commonly remaking the wealth of sociality), a biopolitics from below" (2013: 18).Specific to the working lives of media professionals, several scholars have begun to document new forms of collective organising- such as online support networks, alternative unions, the formation of semipermanent workgroups, and so on - among workers in digital games, journalism, film and television.

The productive potential of precarity is not limited to (new) forms of collective organisation but can perhaps also include different perspectives on the helplessness and vulnerability that comes with a lack of power and control over one's future. As numerous authors signal, the complex nature of society manifests itself not just in the domains of work, finance or politics, but determines all aspects of life. Whereas the unpredictability and uncontrollability of the future can be perceived as a problematic feature that renders us helpless and vulnerable, it also can be explored for its agentic potential through cultivating what Riel Miller calls 'non-predictive narratives' produced by 'what if' imagining guided by spontaneity, experimentation and learning-by-doing(2007: 342-3).Miller developed this approach to engage with an unknowable and unpredictable future into the UNESCO 'Futures Literacy' programmeiii, aiming to help people (individually and collectively) 
to think about our precarious relationship to what comes next in terms of 'anticipatory systems' - that is: to always be able to distinguish three types of future: contingent - caused by an external event such as the current coronavirus crisis; optimised - a future that we can somehow plan and control for; and explorative - based on seeing the present differently and identifying novel ways of making sense of what is going on (Miller, 2011). Miller suggests that much of our debilitating feelings about the future and our lack of control over it stem from an under-developed"capacity to discover and invent anticipatory assumptions" (27).

The UNESCO approach has led to the formation of numerous 'Futures Literacy Labs' all over the world - and particularly across the Global South. Although we are not aware of concrete applications of the futures literacy approach among media workers, the approach is mentioned here as it is a good example of thinking differently about the future, and more specifically, of operationalising one's lack of control over that future as something other than mere helplessness and insecurity. We hypothesise that media professionals - particularly those working under conditions of NSE - often enact all kinds of explicit and implicit anticipatory tactics and strategies that warrant our attention as students and scholars of media work.

\section{Agency}

A final comment in this mapping essay engages with the question of autonomy and agency. Although these terms are sometimes used interchangeably, they refer to distinct modes of being when it comes to (media) work. Autonomy tends to refer to one's capacity to operate and function without external control over one's actions - which in journalism, for example, means being able to pursue stories and sources without commercial or owner interference. Agency, on the other hand, signals one's ability to make creative decisions within and across a range of options available while on the job. In other words: autonomy is a condition; the agency is an ability. The distinction becomes apparent when considering their mutual exclusivity: one can be creatively autonomous, evidenced by the entrepreneurial rhetoric surrounding the self-employed professional free to choose her clients while simultaneously being 
without agency, as the projects she ends up working on can be highly prescribed and formulaic. Sometimes, agency means sticking to well-established routines, formats and formulas in media work in the absence of variables that would empower autonomous work - which would include an ability to imagine radically different ways of doing things.

What binds almost everyone in cultural, creative and media work is a desire for autonomy (Deuze 2007). In much of the literature on atypical (media) work, such a more or less universal quest for creative autonomy has consistently been framed as perhaps desirable yet inevitably constrained. Banks, on the other hand, argues that cultural and creative work is intrinsically autonomous where workers consider it essential to do their artistic, creative and aesthetic work, while managers and firms recognise that without some kind of autonomy, there would not be enough variety of product to market effectively. In his studies on how workers manage and practise autonomy, Banks finds "a kind of socially embedded, compromised or 'negotiated' autonomy that is now more prevalent amongst cultural workers engaged in routine production" (2010: 252). Subsequent work indeed suggests that, much like notions of good or bad work, autonomy is a deeply ambivalent and context-dependent concept in media work.

We intervene in these debates to imagine and identify autonomy and agency as a collective rather than individual-level conditions and capacities. How can we propel atypical media workers to organise, to engage in some kind of collective action, to rise and realise their worth in an industry that is growing much faster than employment keeps up with it? Perhaps one way of doing so is by identifying forms of autonomy and agency beyond the individual. For example, at the moment we are all working within a network of scholars who, in different ways, investigate ways in which media and cultural works can collaborate and establish forms of agency and autonomy through reflective action (Ramaker, Van der Stoep and Deuze 2015), artist-journalism fusion and collaboration (Postema and Deuze, 2020), developing a shared learning culture in newsrooms (Porcu, 2017), as well as through re-imagining 'dreamjobs' in the audiovisual industry (Kotišová 2019), freelance journalism (Arends and Van 't Hof, 2020), and the gig economy 
(Newlands and Fieseler 2020)iv. Although none of us set out in advance to find forms and opportunities for collective/collaborative autonomy, all of us ended up seeing beyond the limitations of the individual toward shared notions of action, reflection, learning and agency. This can be considered to be spontaneous operationalisation of social hope and shared narratives guiding our research on atypical work, and as a way of taking responsibility for the positions advocated in this essay.

\section{Discussion}

In this essay, it is argued how most creative labour (in general, and media work in particular) takes place under atypical conditions, and while it is a particular feature of contemporary capitalist culture, it is perhaps best conceived as a historical condition. The dualisms dominating the discourse on atypical media work - such as contracted versus freelance labour, primary and secondary sector employment, good versus bad jobs, paid versus unpaid work - are not as useful as they seem to be, complicating quick conclusions and complicating solutions to the potential problems that non-standard employment brings. Third, we put forward the productive potential of the key problematic features of atypical work: precarity, precariousness, constrained autonomy and lack of agency. Throughout our argument, the reasons and motivations for studying atypical media work are articulated with a distinct sense of social hope.

As non-standard employment becomes the norm for labour arrangements in the creative industries generally, and the media, in particular, it is crucial we articulate our theory and research more closely to the complex, ambivalent yet also pleasurable and transformative elements of atypical work. We locate progressive potential in deliberately hopeful notions of shared agency and engaged scholarship to move toward productive notions of precarity. The productive aspects of precarious work in the media do not necessarily relate to industrial notions of productivity, but rather refer to giving rise to a new, innovative or just different ways of thinking about one's predicament, and to imagine other ways of working and being at work. 


\section{References}

Allison A. (2013) Precarious Japan. Durham, NC: Duke Univ. Press.

Archetti, C.(2020) Research, methods, and the Zen art of questioning what you know. Norsk Medietidsskrift 107(2), 1-7, DOI: https:// doi.org/ 10.18261/ISSN.0805-9535-2020-02-06.

Arends, S., Van 't Hof, E. (2020) De nieuwe journalist. Amsterdam: AUP. Banks, M. (2010) Autonomy Guaranteed? Cultural Work and the "ArtCommerce Relation", Journal for Cultural Research, 14:3, 251-269, DOI: $10.1080 / 14797581003791487$.

Banks, M. (2017) Creative justice. London: Rowman \& Littlefield.

Banks, M. (2019). Precarity, Biography, and Event: Work and Time in the Cultural Industries. Sociological Research Online, 24(4), 541-556, DOI: https://doi.org/10.1177/1360780419844526.

Beck, U (2002) Zombie categories: An interview with Ulrich Beck. In: Beck, U, Beck-Gernsheim, E, Individualization: Institutionalized Individualism and Its Social and Political Consequences. London: Sage, 202-213.

Butler, J. (2004) Precarious life. New York: Verso.

Butler, J. (2016) Towards a Performative Theory of Assembly. Cambridge, MA: Harvard University Press.

Charhon, P., Murphy, D. (2016) The Future of Work in the Media, Arts \& Entertainment Sector: Meeting the Challenge of Atypical Working. Source: Research report. URL: https://www.fim-musicians.org/wpcontent/uploads/atypical-work-handbook-en.pdf.

Deuze, M.(2007) Media Work. Cambridge: Polity Press.

Deuze, M.(2012). Media Life. Cambridge: Polity Press.

Deuze, M., Prenger, M. (Eds) (2019). Making Media. Amsterdam: AUP.

Giddens, A. (1984). The constitution of society. Cambridge: Polity Press.

Gill, R., Pratt, A. (2008) The Social Factory? Immaterial Labour, Precariousness and Cultural Work. Theory, Culture and Society 25(78), pp.1-30.

Gregg M (2011) Work's intimacy. Cambridge: Polity.

Gregg, M. (2009) Learning to (Love) Labour: Production Cultures and the Affective Turn, Communication and Critical/Cultural Studies, 6:2, 209-214.

Hesmondhalgh, D., Baker, S. (2010). 'A very complicated version of freedom': Conditions and experiences of creative labour in three cultural industries. Poetics 38, 4-20.

Hesmondhalgh, D., Baker, S. (2011). Creative labour: media work in three cultural industries. London: Routledge.

International Labour Organization (2006) The changing nature of work: a global survey and case study of atypical work in the media industry. 
Mark Deuze et al. Toward a Theory of Atypical Media Work and Social Hope

Research report. URL: http://ilo.org/ sector/ Resources/ publications/ WCMS_161547/lang--en/index.htm.

Kotišová, J. (2019) Devastating Dreamjobs. Iluminace 31(4), 27-45.

Kotišová, J. (2020) An elixir of life? Emotional labour in cultural journalism. Journalism.DOI: https:/ / doi.org/10.1177/14648849209172 89.

Mayer, V. (2008). 'Studying up and $\mathrm{f}^{* *} \mathrm{cking}$ up: Ethnographic interviewing in production studies', Cinema Journal, 47(2), 141-148.

Media Practice and Its Challenges for Journalism Studies. International Journal of Communication 14(2020), 2868-2886.

Miller, R. (2007) Futures literacy: A hybrid strategic scenario method. Futures 39, 341-362.

Miller, R. (2011) Futures Literacy - Embracing Complexity and Using the Future. Ethos 10, 23-28.

Newlands, G., Fieseler, C. (2020) \# dreamjob: navigating pathways to success as an aspiring Instagram influencer. In: Goanta, C., Ranchordás, S. (Eds), The Regulation of Social Media Influencers, 167184. London: Edward Elgar.

Postema, S., Deuze, M. (2020) Artistic Journalism: Confluence in Forms, Values and Practices, Journalism Studies, DOI: 10.1080/ 1461670X. 2020.1745666.

Raetzsch, C., Lünenborg, M. (2020) Anchoring Practices for Public Connection:

Ramaker, T., Van der Stoep, J., Deuze, M. (2015) Reflective Practices for Future Journalism: The Need, the Resistance and the Way Forward, Javnost - The Public, 22:4, 345-361, DOI: 10.1080/ 1318322. 2015.1091622.

Rorty, Richard (1999) Philosophy and social hope. New York: Penguin.

Ross, A. (2008) The New Geography of Work Power to the Precarious? Theory, Culture \& Society 25(7-8), 31-49.

Rottwilm, P. (2014) The Future of Journalistic Work: Its Changing Nature and Implications. Reuters Institute for the Study of Journalism report. URL: https://reutersinstitute.politics.ox.ac.uk/our-research/futurejournalistic-work.

Sennett, R. (2006), The culture of the new capitalism. New Haven: Yale University Press.

Wilkes, M., Carey, H., Florisson, R. (2020) The Looking Glass: Mental health in the UK film, TV and cinema industry. Report. URL: https:/ / filmtvcharity.org.uk/news-event/through-the-looking-glass.

Witschge, T., Deuze, M.(2020) Beyond Journalism. Cambridge: Polity Press.

Wright Mills, C. (1959) The Sociological Imagination. Oxford: OUP. 


\section{Endnotes}

i To illustrate this point: at the IAMCR annual conference of 2019 we organized a panel session on creative ways of scholarship and being an academic. Panelists involved: Cristina Archetti, Johana Kotišová, Ana Serrano Tellería, Julia Giese, Nick Couldry and Mark Deuze.

ii See also: https://www.ilo.org/infostories/Stories/Employment/NonStandard-Employment.

iii See: https://en.unesco.org/themes/futures-literacy.

iv These references are to PhD students Ornella Porcu, Erwin van 't Hof, Timon Ramaker, Stijn Postema and Gemma Newlands, and Marie Curie Fellow Johana Kotišová, working informally together in a research team at the University of Amsterdam under the supervision of Mark Deuze. 